\title{
Flame spread over the surface of thermal insulation materials in different environments
}

\author{
HUANG XinJie, SUN JinHua*, JI Jie, ZHANG Ying, WANG QingSong \& ZHANG Yi \\ State Key Laboratory of Fire Science, University of Science and Technology of China, Hefei 230026, China
}

Received March 18, 2010; accepted September 10, 2010; published online April 13, 2011

\begin{abstract}
Experiments were conducted in a plateau area in Lhasa and a plain area in Hefei China to investigate the flame spread characteristics on thermal insulation materials under different environmental conditions (pressure and oxygen concentration). Molded polystyrene foam (EPS) and extruded polystyrene foam (XPS) samples were placed horizontally on a small-scale flame spread experimental bench. Changes in the average length of the pool fire, flame spread speed,average flame height, and length of preheating zone were used to determine the effect of the plateau and plain environments on flame spread characteristics. These parameters were all larger in Hefei than in Lhasa, which indicates the fire hazard in Hefei will be higher than that in Lhasa if insulation materials of the same size are used.
\end{abstract}

thermal insulation material, molded polystyrene foam, extruded polystyrene foam, hypobaric hypoxia, flame spread speed

Citation: Huang X J, Sun J H, Ji J, et al. Flame spread over the surface of thermal insulation materials in different environments. Chinese Sci Bull, 2011, 56: 1617-1622, doi: 10.1007/s11434-010-4187-z

Global energy problems are one of the major constraints on growth of the world economy and sustainable development. The energy consumption of buildings in China is a major problem. Therefore, energy-efficient building methods are a focus of development. External insulation materials provide good insulation and are widely used in high-rise buildings. Currently, both international and Chinese high-rise buildings mainly use organic polymer foam insulation boards for thermal insulation. These materials include molded polystyrene foam (EPS) and extruded polystyrene foam (XPS). Fire safety is a concern with these insulation materials as they rapidly combust and show high heat release, flame temperature, smoke volume, and release of toxins. A fire involving these materials occurred on February 9, 2009, on the north side of the China Central Television (CCTV) building. Fireworks lit the insulation material (XPS) in the external facade. The fire spread rapidly, and eventually ignited the entire building. It resulted in the death of a fireman, injury of seven people, and the direct economic loss of sev-

*Corresponding author (email: sunjh@ustc.edu.cn) eral billion Yuan. This case illustrates the important practical significance of systematic studies on the spread of fire in insulation materials. Flame spread speed in many cases determines the severity of the fire. Flame spread characteristics have been evaluated in a number of different insulation materials. Lie [1] studied flame spread in two typical insulation materials, the thermoplastic EPS and the thermoset plastic polyurethane foam PU, in hollow walls created by two concrete slabs with different-sized air gaps. Oleszkiewicz [2] measured full-size flame spread characteristics, including the distance of flame spread and the maximum heat flux, in exterior insulation materials to evaluate the fire risk of different insulation materials. The changes in flame speed have also been investigated in many typical foams and other combustible materials placed horizontally under external radiation [3]. Liang et al. [4] studied decorative thermoplastic EPS using the large-scale ISO9705 test. They attributed the flame spread of the insulating materials to flow combustion, and the liquidity of molten materials was an important factor in this combustion. However, there are few studies that have 
investigated flame spread characteristics of materials under different environmental conditions, such as pressure and oxygen concentration. These studies include an investigation of the flame spread characteristics of white wood carbonized solid fuel at high altitude, and the comparison of flame spread speed, flame height, flame temperature and other parameters in Lhasa and Hefei, China [5-7]. In consideration of the large size of China, and the resulting large temperature gradients north to south and changes in altitude east to west, studies of flame spread of insulation materials under different conditions are practically important.

In this paper, small-scale EPS and XPS flame spread experiments were conducted in a plateau area in Lhasa and a plain area in Hefei. Insulation material of the same size was placed horizontally and ignited, and the average length of the pool fire, flame spread speed, average flame height and length of preheating zone were analyzed.

\section{Experimental}

\subsection{Experimental system}

Experiments were carried out using a small-scale flame spread setup (Figure 1) including a rotating support of gypsum board and a measurement system. Insulation materials could be placed at different angles on the gypsum board to perform one-sided flame spread experiments. The measurement system included a thermocouple, radiation heat flow meter, camera and data acquisition system, and a heat flux acquisition device. The gas temperature and internal temperatures of the insulation materials were measured by the thermocouple during the flame spread process. The heat flux meter was used to measure radiation heat flux in the process of flame spread. The camera recorded the flame spread process. The data were used to establish the relationship between insulation material pyrolysis front and flame spread time.

\subsection{Sample preparation and experimental measurement}

Both the insulation materials, EPS and XPS, were of the same size ( $80 \mathrm{~cm}$ length, $4 \mathrm{~cm}$ width, $4 \mathrm{~cm}$ thickness). The densities were 18 and $36 \mathrm{~kg} / \mathrm{m}^{3}$ for EPS and XPS. The bottom surface of each sample was wrapped with aluminum foil to prevent molten insulation materials from flowing onto the gypsum board. A set of parallel lines were drawn at 5 -cm intervals on the upper surface of each sample to facilitate instantaneous recording of the position of the pyrolysis front during flame spread. Before the experiment, the sample was placed on the gypsum board and the thermocouple was positioned on the upper surface in the middle to measure the surface temperature during flame spread.

\section{Results and discussion}

The flame spread experiments were carried out in Lhasa and Hefei, which have different geographical and meteorological conditions (Table 1).

The Lhasa area is hypobaric and hypoxic, while Hefei has normal pressure and oxygen concentration. Flame spread experiments in these two locations can represent the characteristics of flame spread at different atmospheric pressure and oxygen concentration.

\subsection{Flame spread characteristics}

The insulation materials EPS and XPS are typical thermo-

Table 1 Geographical and meteorological conditions in Lhasa and Hefei (China)

\begin{tabular}{cccccc}
\hline Places & $\begin{array}{c}\text { Atmospheric } \\
\text { pressure } \\
(\mathrm{kPa})\end{array}$ & $\begin{array}{c}\text { Absolute } \\
\text { oxygen } \\
\text { concentration } \\
(\%)\end{array}$ & $\begin{array}{c}\text { Air } \\
\text { density } \\
\left(\mathrm{kg} \mathrm{m}^{-3}\right)\end{array}$ & $\begin{array}{c}\text { Relative } \\
\text { humidity } \\
(\%)\end{array}$ & $\begin{array}{c}\text { Ambient } \\
\text { temperature } \\
(\mathrm{K})\end{array}$ \\
\hline Lhasa & 65.5 & 13.2 & 0.83 & 25 & 297 \\
Hefei & 101.8 & 21.0 & 1.28 & 35 & 295 \\
\hline
\end{tabular}


(b)

Figure 1 Small-scale experimental system used to study flame spread on insulation materials. (a) Rotary experimental stent system; (b) measurement system of flame spread characteristics. 
plastic materials, and each has a characteristic combustion process. The flame shapes can reflect the characteristics of flame spread on the insulation material, and those for the EPS sample in Lhasa are shown in Figure 2. EPS, XPS and other thermoplastic solid materials have a different flame spread process to carbonized solid materials. The combustion zone on thermoplastic materials has two parts (Figure 3 ). Flame zone I is the solid surface flame area, in which the unburnt material, shrinks, melts, pyrolyzes, foams and vaporizes due to the heat energy it receives from the flame. Flame zone II is the pool fire area, which forms on the unconsumed EPS liquid after flame zone I has passed. The length and maximum flame height of pool fire are indicated in Figure 3.

\subsection{Pool fire length and maximum flame height}

As the thermoplastic material heats, it softens and eventually liquefies. This may increase the fire hazard of the thermoplastic material by accelerating flame spread speed through the flow of flammable liquid. Alternatively, it may limit fire development by reducing the fuel load near the source of the fire through flow of the flammable liquid. Therefore, the changes in pool fire length during the flame spread process have practical application in the study of fire hazards. The changes in the pool fire length with the flame spread time on EPS in Lhasa and Hefei were obviously different (Figure 4).

In Lhasa the average length of the pool fire on EPS $(23.13 \mathrm{~cm})$ was much lower than that in Hefei $(33.48 \mathrm{~cm})$. The maximum pool fire length in Lhasa $(26 \mathrm{~cm})$ was also less than that in Hefei $(39 \mathrm{~cm})$. These results illustrate the effect of atmospheric pressure and oxygen concentration on the pool fire length.

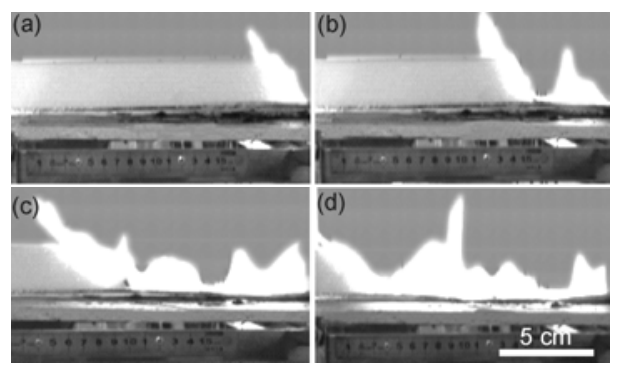

Figure 2 Flame shapes at different flame spread time on the EPS sample in Lhasa. (a) $30 \mathrm{~s}$; (b) $60 \mathrm{~s}$; (c) $90 \mathrm{~s}$; (d) $120 \mathrm{~s}$.

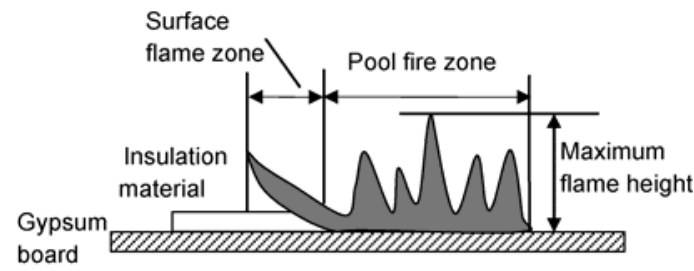

Figure 3 Schematic of surface flame spread on thermoplastics.


Figure 4 Pool fire length during the flame spread process on EPS in Lhasa and Hefei. (a) Lhasa; (b) Hefei.

The EPS pool fire length in both Lhasa and Hefei displayed cyclical fluctuations (Figure 4). These cycles involved an initial increase in the pool fire length to a maximum, which was followed by a rapid decrease, and then an increase again. These cycles occur due to the flame spread characteristics of thermoplastic material (Section 2.1), where the zone II pool fire takes some time to consume the available material. During this cyclical increasing of the pool fire length,the speed at which the flame front of zone I spreads $\left(v_{f}\right)$ is greater than the speed at which the flame of zone II moves forward,which is also called the material burnout rate $\left(v_{b}\right)$.

The position of the zone I pyrolysis front with time (Figure 5) was used to evaluate the flame spread speed on EPS. In both Lhasa and Hefei, a linear relationship was observed, which indicates the flame spread speed did not change over time. The flame spread speed was calculated as $0.31 \mathrm{~cm} / \mathrm{s}$ in Hefei and $0.22 \mathrm{~cm} / \mathrm{s}$ in Lhasa.

Surface flame spread speed on thermoset material depends on the heat of the flame back to the pyrolysis zone, and follows the flame spread speed formula [8]:

$$
\rho v_{f} \Delta H=q_{v},
$$

where $q_{v}$ is the heat flux of the pyrolysis front and $\Delta H$ is the enthalpy change of the thermoset material. $\Delta H$ is given by 

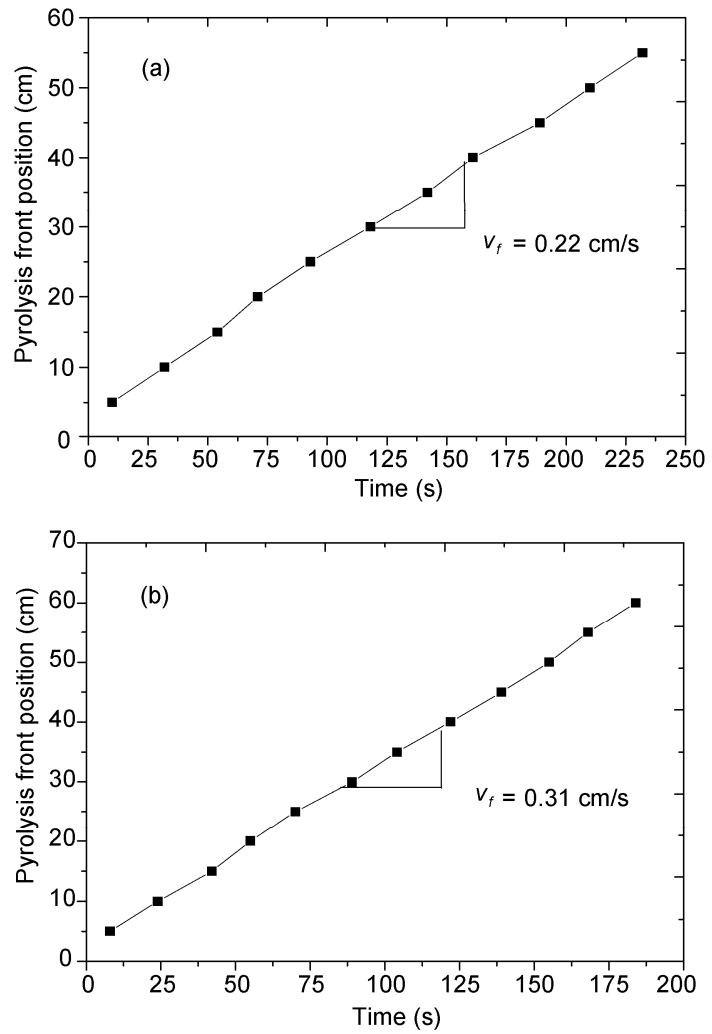

Figure 5 Position of the zone I pyrolysis front with time on EPS in Lhasa and Hefei. (a) Lhasa; (b) Hefei.

$$
\Delta H=c_{p}\left(T_{i g}-T_{s}\right)+L_{v},
$$

where $c_{p}$ is the specific heat of the material, $T_{i g}$ is the ignition temperature, $T_{s}$ is the initial temperature, and $L_{v}$ is the latent heat of vaporization of the material. For the EPS insulation material $q_{v}$ is the sum of the radiative heat flux $q_{r v}$ and conductive heat flux $q_{c v}, q_{v}=q_{r v}+q_{c v}$, but does not include the convective heat flux. This can also be expressed as

$$
q_{v}=\varepsilon \sigma\left(T_{f}{ }^{4}-T_{i g}{ }^{4}\right)+\left.\lambda_{s}\left(\frac{\mathrm{d} T}{\mathrm{~d} x}\right)\right|_{x=0},
$$

in which, $T_{f}$ is the average temperature of the flame, $\varepsilon$ is the flame emissivity, $q_{r v}=\varepsilon \sigma\left(T_{f}^{4}-T_{i g}{ }^{4}\right), \quad q_{c v}=\left.\lambda_{s}\left(\frac{\mathrm{d} T}{\mathrm{~d} x}\right)\right|_{x=0}$, and $x=0$ represents the location of the pyrolysis front. As discussed earlier, on EPS $v_{f}>v_{b}$, or in other words the heat flux of the pyrolysis front $\left(q_{v}\right)$ is less than $\rho v_{f} \Delta H$, which can be rearranged to give $\frac{q_{v}}{\Delta H \rho}<v_{f}$. Meanwhile, $q_{v}$ should be greater than the heat flux that is required to initiate pyrolysis of EPS. That is $c_{p} \rho v_{\mathrm{f}}\left(T_{i g}-T_{s}\right)<q_{v}$, which can be rearranged as $v_{f}<\frac{q_{v}}{c_{p} \rho\left(T_{i g}-T_{s}\right)}$. In summary:

$$
\frac{q_{v}}{\Delta H \rho}<v_{f}<\frac{q_{v}}{c_{p} \rho\left(T_{i g}-T_{s}\right)} .
$$

By substituting eq. (3) into eq. (4), we obtain

$$
\begin{gathered}
\frac{\varepsilon \sigma\left(T_{f}{ }^{4}-T_{i g}{ }^{4}\right)+\left.\lambda_{s}\left(\frac{\mathrm{d} T}{\mathrm{~d} x}\right)\right|_{x=0}}{\Delta H \rho}<v_{f} \\
<\frac{\varepsilon \sigma\left(T_{f}{ }^{4}-T_{i g}{ }^{4}\right)+\left.\lambda_{s}\left(\frac{\mathrm{d} T}{\mathrm{~d} x}\right)\right|_{x=0}}{c_{p} \rho\left(T_{i g}-T_{s}\right)} .
\end{gathered}
$$

The pool fire on EPS consists of several cycles as described earlier, so eq. (4) describes the entire process of flame spread.

Figure 6 presents the change in maximum pool fire flame height with flame spread time on EPS in Lhasa and Hefei. In Hefei the average maximum flame height was $10.07 \mathrm{~cm}$, while in Lhasa it was $2 \mathrm{~cm}$ lower at $8.07 \mathrm{~cm}$. This difference in the flame height occurs because the combustion of EPS in both Lhasa and Hefei involves a diffusion flame. Under normal pressure, oxygen is supplied to a diffusion flame by natural convection and diffusion [9]. Lhasa is a hypobaric, hypoxic environment, and has a lower air density than in Hefei (Table 1). This reduces the buoyancy of the air, and consequently reduces natural convection in Lhasa. The result is a decreased oxygen supply and lower maximum flame height than in Hefei.
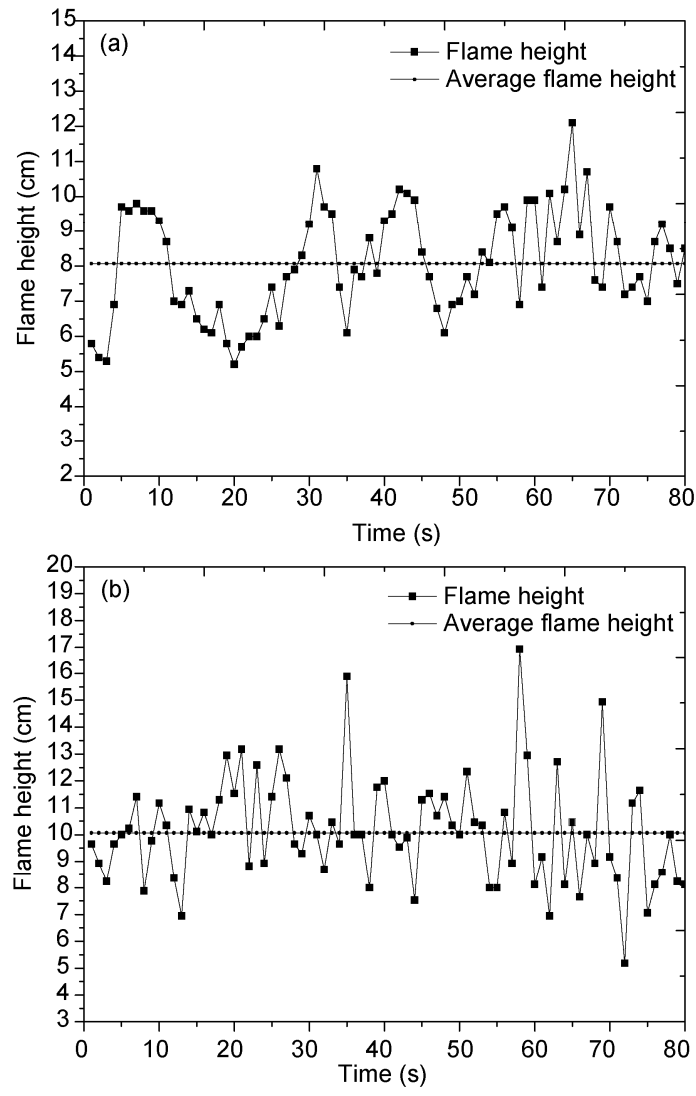

Figure 6 Maximum flame height during flame spread on EPS in Lhasa and Hefei. (a) Lhasa; (b) Hefei. 
The experimental results detailed above indicate that for horizontally placed EPS, there is essentially no difference in the flame spread process in Lhasa and Hefei. However, in the hypobaric, hypoxic environment of Lhasa, the average length of the pool fire and the maximum flame height are smaller than that in Hefei. This indicates the volume of the pool fire flame is greater in Hefei than in Lhasa. The rate of heat release per unit time in Hefei will be higher than that in Lhasa for EPS materials of the same size. Consequently, the fire hazard will be higher in Hefei than Lhasa.

We used the same method to analyze the flame spread characteristics of XPS in Lhasa and Hefei. In this case, the pool fire length constantly increased over the entire flame spread process (Figure 7), and the cyclical growth of pool fire length we observed with EPS did not occur. This is because while both EPS and XPS are polystyrene foam materials, the density of XPS is about twice that of EPS. Therefore, for samples of the same size, the unit length of XPS fueling the pool fire is about twice that of EPS. Consequently,the XPS pool fire can burn for longer during the process of flame spread. The flame spread speed on XPS is also expressed by eq. (4).

The average length of the pool fire on XPS was $32 \mathrm{~cm}$ in Hefei and $20.5 \mathrm{~cm}$ in Lhasa. The average maximum flame heights were $9.3 \mathrm{~cm}$ in Lhasa and $10.0 \mathrm{~cm}$ in Hefei. The flame spread speeds in Lhasa and Hefei were $0.12 \mathrm{~cm} / \mathrm{s}$, and $0.22 \mathrm{~cm} / \mathrm{s}$, respectively. These parameters for XPS were all lower in Lhasa than Hefei, which was also observed with EPS.

\subsection{Length of the preheating zone}

During the flame spread on the surface of insulation material, the unburnt material at the pyrolysis front receives both radiative and conductive heat fluxes. This brings it to pyrolysis temperature, which results in generation of flammable gas and then combustion of this material. The flame spread speed can be expressed as

$$
\rho c_{p} v_{f} d\left(T_{i g}-T_{s}\right)=q_{v} \delta_{f},
$$

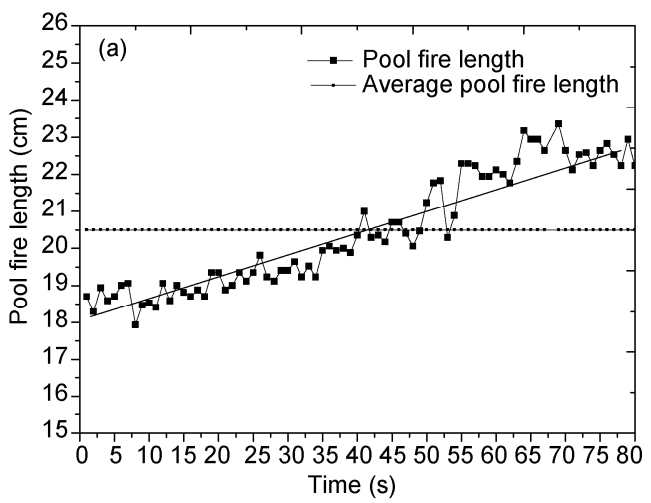

where $d$ is the material thickness, $c_{p}$ is the specific heat of the insulation material, and $\delta_{f}$ is the length of the preheating zone. Eq. (6) then becomes

$$
v_{f}=\frac{q_{v} \delta_{f}}{\rho c_{p} d\left(T_{i g}-T_{s}\right)},
$$

in which $\rho, c_{p}, d, T_{i g}$ and $T_{s}$ have the same values in Lhasa and Hefei. Therefore, the heat flux $q_{v}$ at the pyrolysis front and preheating zone length $\delta_{f}$ directly affect the flame spread speed on the insulation material. The preheating zone length can be calculated from the temperature gradient (Figure 8) on the surface of the insulation material, which was recorded by the thermocouple.

In Figure 8, the origin is the position of the pyrolysis front and the $x$-axis represents the distance from the surface of the insulation material to the pyrolysis front. The preheating zone length is defined by the equation, $\delta_{f}=\left(T_{i g}-T_{\infty}\right) /$ $\left|\mathrm{d} T_{s} / \mathrm{d} x\right|_{\max }[10]$, in which the EPS ignition temperature $\left(T_{i g}\right)$ is $373^{\circ} \mathrm{C}$. The preheating zone length for EPS was $2.49 \mathrm{~cm}$ in Lhasa and $2.9 \mathrm{~cm}$ in Hefei. For XPS, the length of preheating zone was $3.0 \mathrm{~cm}$ in Lhasa and $3.48 \mathrm{~cm}$ in Hefei.

On both EPS and XPS, the length of the preheating zone was only slightly larger in Hefei than in Lhasa. Therefore, the heat flux of the pyrolysis front will be the main factor affecting the flame spread speed on the insulation material. From the formula $v_{f}=\frac{q_{v} \delta_{f}}{\rho c_{p} d\left(T_{i g}-T_{s}\right)}$, we can deduce that $v_{f}<\frac{q_{v}}{\rho c_{p}\left(T_{i g}-T_{s}\right)}$. Simultaneously, the pool fire forms on molten insulation material and there is little vaporized material at the pyrolysis front; therefore, the flame spread speed is close to $\frac{q_{v}}{\rho c_{p}\left(T_{i g}-T_{s}\right)} \cdot \Delta H$ in the flame spread process is the same for both EPS and XPS at $1.6 \mathrm{~kJ} / \mathrm{g}$, and we have $\frac{q_{v}}{\Delta H \rho}<v_{f}$. The range of the flame spread speed is within these two limits.

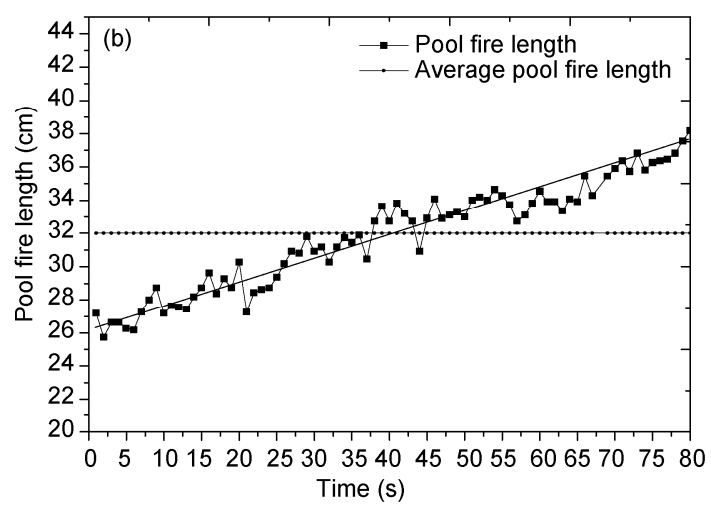

Figure 7 Length of pool fire on XPS in Lhasa and Hefei. (a) Lhasa; (b) Hefei. 

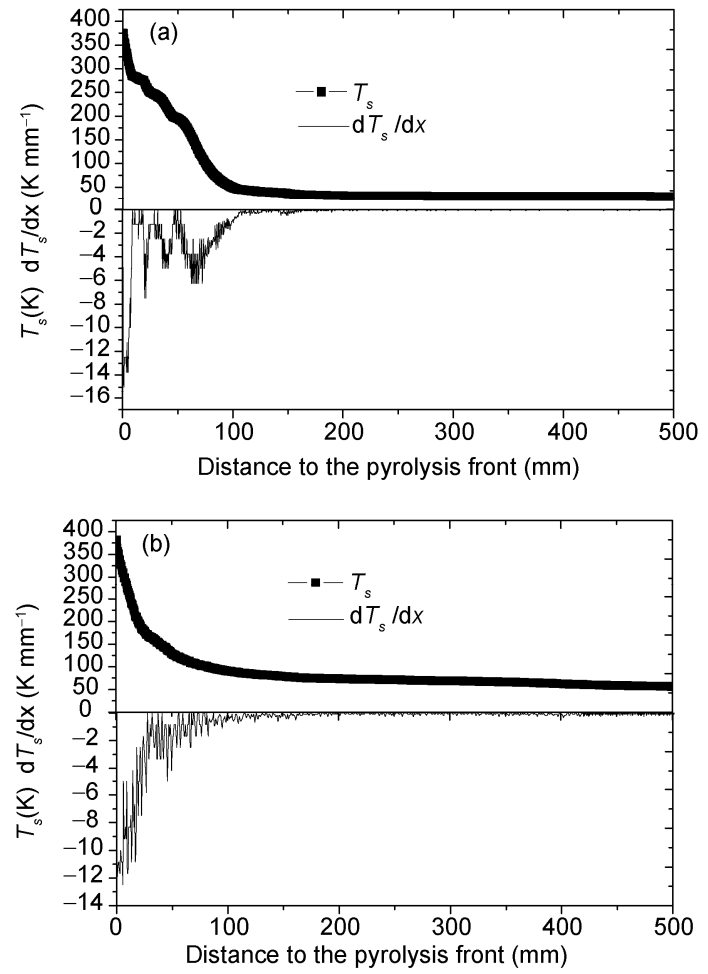

Figure 8 Surface temperature gradient during flame spread on EPS in Lhasa and Hefei. (a) Lhasa; (b) Hefei.

\section{Conclusions}

Small-scale flame spread experiments were conducted in Lhasa and Hefei using common insulation materials, EPS and XPS. The average length of pool fire, flame spread speed, average maximum flame height, and length of the preheating zone were determined on horizontally placed insulation materials ( $80 \mathrm{~cm}$ long, $4 \mathrm{~cm}$ wide, $4 \mathrm{~cm}$ thick). The following conclusions were drawn for horizontal insulation materials:
(1) The EPS pool fire length increases cyclically but that for XPS does not.

(2) The flame spread speed on EPS and XPS is between

$$
\frac{q_{v}}{\Delta H \rho} \text { and } \frac{q_{v}}{\rho c_{p}\left(T_{i g}-T_{s}\right)} \text {. }
$$

(3) The experimental average length of pool fire, flame spread speed, average maximum flame height, and preheating zone length of EPS and XPS in Hefei were higher than those in Lhasa.

This work was supported by the National Natural Science Foundation of China (50976110) and China Postdoctoral Science Foundation (20090450703).

1 Lie T T. Contribution of insulation in cavity walls to propagation of fire. Fire Study No.29 of the Division of Building Research,1972. 12

2 Oleszkiewicz I. Fire exposure to exterior walls and flame spread in combustible cladding. Fire Technol, 1990, 25: 357-375

3 Zou Y H, Zhou J J, Zhong Z R, et al. Experimental investigation of flame spread on horizontal combustible surface with external radiation(in Chinese). J Chin Univ Sci Tech, 2001, 31: 465-469

4 Xu L, Zhang H P, Wan Y T, et al. Large-scale fire test on thermoplastic linings(in Chinese). J Chin Univ Sci Tech, 2008, 38: 563-68

5 Li J, Ji J, Zhang Y, et al. Characteristics of flame spread over the surface of charring solid combustibles at high altitude. Chinese Sci Bull, 2009, 54: 1127-1132

6 Sun X Q, Li Y Z, Huo R, et al. Experimental on ignition characteristics of timber widely used in Tibet's historical buildings(in Chinese). J Chin Univ Sci Tech, 2006, 36:77-80

7 You F, Hu Y, Song L. On the combustion properties of decorative textiles applied in ancient Tibetan buildings(in Chinese). J Chin Univ Sci Tech, 2007, 37: 284-289

8 Williams F A. Mechanisms of fire spread. P Combust Inst, 1976, 16: 1281-1294

9 Wang W G, Kong W J, Zhang P Y. Experimental studies on flame spread across thermally thin solid fuel surfaces under lower ambient pressures(in Chinese). J Eng Thermophys, 2004, 25: 887-890

10 Bhattacharjee S, Altenkirch R A, Sacksteder K. The effect of ambient pressure on flame spread over thin cellulosic fuel in a quiescent microgravity environment. J Heat Trans, 1996, 118: 181-190

Open Access This article is distributed under the terms of the Creative Commons Attribution License which permits any use, distribution, and reproduction in any medium, provided the original author(s) and source are credited. 